\title{
Lead Slowing Down Spectrometer FY2013 Annual Report
}

$\begin{array}{ll}\text { GA Warren } & \text { A Weltz }^{2} \\ \text { J Kulisek } & \text { J Harris }^{3} \\ \text { V Gavron }^{1} & \text { T Stewart }^{3} \\ \text { Y Danon }^{2} & \end{array}$

October 2013

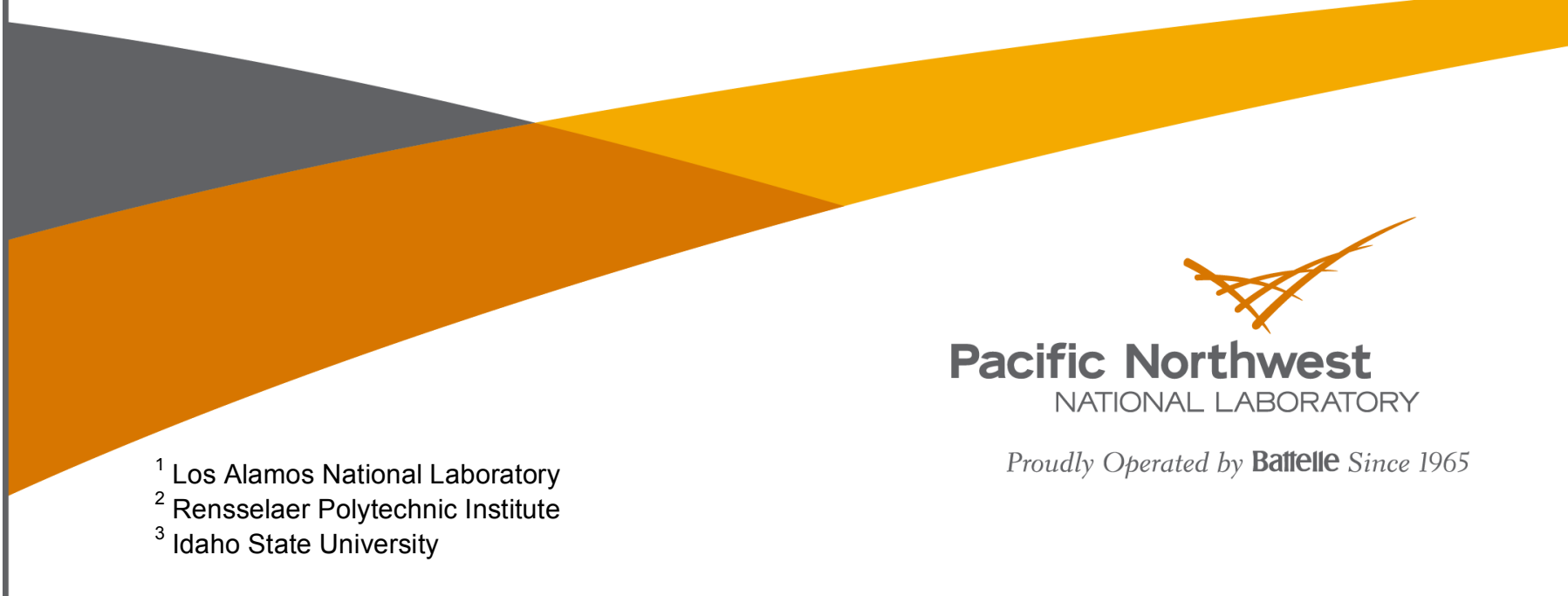




\title{
DISCLAIMER
}

This report was prepared as an account of work sponsored by an agency of the United States Government. Neither the United States Government nor any agency thereof, nor Battelle Memorial Institute, nor any of their employees, makes any warranty, express or implied, or assumes any legal liability or responsibility for the accuracy, completeness, or usefulness of any information, apparatus, product, or process disclosed, or represents that its use would not infringe privately owned rights. Reference herein to any specific commercial product, process, or service by trade name, trademark, manufacturer, or otherwise does not necessarily constitute or imply its endorsement, recommendation, or favoring by the United States Government or any agency thereof, or Battelle Memorial Institute. The views and opinions of authors expressed herein do not necessarily state or reflect those of the United States Government or any agency thereof.

\author{
PACIFIC NORTHWEST NATIONAL LABORATORY \\ operated by \\ BATTELLE \\ for the \\ UNITED STATES DEPARTMENT OF ENERGY \\ under Contract DE-AC05-76RL01830 \\ Printed in the United States of America
Available to DOE and DOE contractors from the Office of Scientific and Technical Information, P.O. Box 62, Oak Ridge, TN 37831-0062; ph: (865) 576-8401 fax: $(865)$ 576-5728
email: reports $\boldsymbol{a}$ adonis.osti.gov \\ Available to the public from the National Technical Information Service \\ 5301 Shawnee Rd., Alexandria, VA 22312 \\ ph: (800) 553-NTIS (6847) \\ email: orders $\omega$ ntis.gov $<$ http://www.ntis.gov/about/form.aspx $>$ \\ Online ordering: http://www.ntis.gov
}




\section{Lead Slowing Down Spectrometer FY2013 Annual Report}

$\begin{array}{ll}\text { GA Warren } & \text { A Weltz }^{2} \\ \text { J Kulisek }^{\text {V Gavron }}{ }^{1} & \text { J Harris }^{3} \\ \text { V G Stewart } & \\ \text { Y Danon2 } & \end{array}$

October 2013

Prepared for

the U.S. Department of Energy

under Contract DE-AC05-76RL01830

Pacific Northwest National Laboratory

Richland, Washington 99352

\footnotetext{
${ }^{1}$ Los Alamos National Laboratory

${ }^{2}$ Rensselaer Polytechnic Institute

${ }^{3}$ Idaho State University
} 



\section{Executive Summary}

The Lead Slowing Down Spectrometry (LSDS) project, funded by the Materials Protection And Control Technology campaign, has been evaluating the feasibility of using LSDS techniques to assay fissile isotopes in used nuclear fuel assemblies. The approach has the potential to provide considerable improvement in the assay of fissile isotopic masses in fuel assemblies compared to other non-destructive techniques in a direct and independent manner. This report is a high level summary of the progress completed in FY2013. This progress included:

- Fabrication of a ${ }^{4} \mathrm{He}$ scintillator detector to detect fast neutrons in the LSDS operating environment. Testing of the detector will be conducted in FY2014.

- Design of a large area ${ }^{232} \mathrm{Th}$ fission chamber.

- Analysis using the Los Alamos National Laboratory perturbation model estimated the required number of neutrons for an LSDS measurement to be $10^{16}$ source neutrons.

- Application of the algorithms developed at Pacific Northwest National Laboratory to LSDS measurement data of various fissile samples conducted in 2012. The results concluded that the ${ }^{235} \mathrm{U}$ could be measured to $2.7 \%$ and the ${ }^{239} \mathrm{Pu}$ could be measured to $6.3 \%$. Significant effort is yet needed to demonstrate the applicability of these algorithms for used-fuel assemblies, but the results reported here are encouraging in demonstrating that we are making progress toward that goal.

- Development and cost-analysis of a research plan for the next critical demonstration measurements. The plan suggests measurements on fresh fuel sub-assemblies as a means to experimentally test self-attenuation and the use of fresh mixed-oxide fuel as a means to test simultaneous measurement of ${ }^{235} \mathrm{U}$ and ${ }^{239} \mathrm{Pu}$. 

PNNL-22920

\section{Acronyms and Abbreviations}

FY

ISU

LANL

LSDS

MOX

MPACT

PNNL

RPI

TRL
Fiscal year

Idaho State University

Los Alamos National Laboratory

Lead Slowing-Down Spectrometry

mixed-oxide

Materials Protection And Control Technology

Pacific Northwest National Laboratory

Rensselaer Polytechnic Institute

Technical Readiness Level 



\section{Contents}

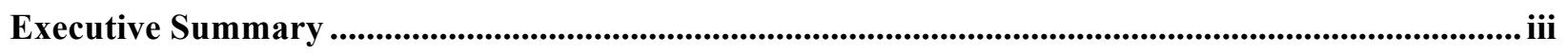

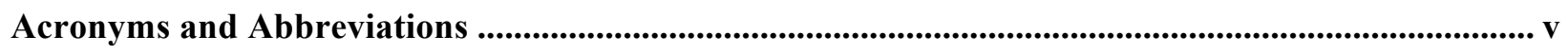

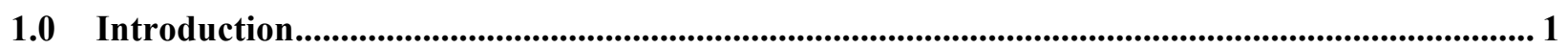

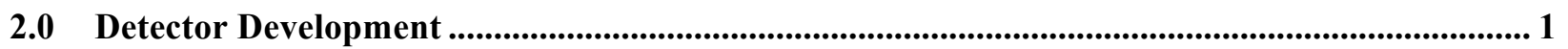

$2.1 \quad$ Large ${ }^{232}$ Th Fission Chamber Design ................................................................................ 1

$2.2{ }^{4} \mathrm{He}$ Scintillator for Fast Neutron Detection......................................................................... 2

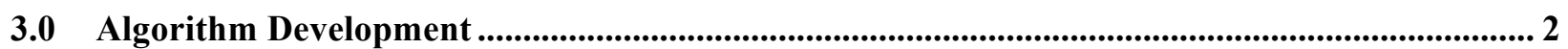

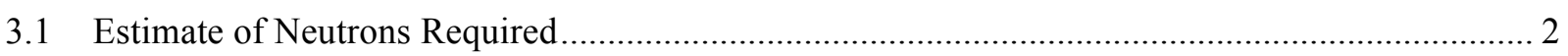

3.2 Applying Algorithms to Measurement Data........................................................................ 2

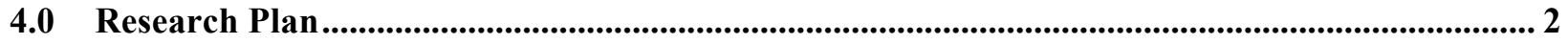

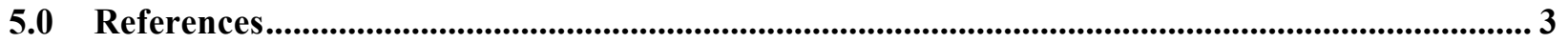





\subsection{Introduction}

Developing a method for the accurate, direct, and independent assay of the fissile isotopes in bulk materials (such as used fuel) from next-generation domestic nuclear fuel cycles is a goal of the Office of Nuclear Energy, Fuel Cycle R\&D, Material Protection and Control Technology (MPACT) Campaign. To meet this goal, MPACT supports a multi-institutional collaboration, of which Pacific Northwest National Laboratory (PNNL) is a part, to study the feasibility of Lead Slowing Down Spectroscopy (LSDS). This technique is an active, nondestructive assay method that has the potential to provide independent, direct measurement of plutonium and uranium isotopic masses in used fuel with an uncertainty considerably lower than the approximately $10 \%$ typical of today's confirmatory methods.

This document is intended as a high-level summary of the collaboration accomplishments for FY2013. The document is divided into three sections: detector development, algorithm development and research plans. In the detector develop, we summarize the Idaho State University's (ISU) progress on the large ${ }^{232}$ Th fission chamber design and provide the status of Los Alamos National Laboratory's (LANL) effort to build and test a ${ }^{4} \mathrm{He}$ scintillator detector. For the algorithm development, we summarize the LANL findings on the required number of neutrons for an LSDS measurement on used fuel and the application of the PNNL-developed algorithms on measurement data that was taken at Rensselaer Polytechnic Institute (RPI) in 2012. This document concludes with a summary of the proposed research plans for the next steps for understanding the feasibility of using LSDS techniques for assay of used fuel.

\subsection{Detector Development}

\subsection{Large ${ }^{232}$ Th Fission Chamber Design}

ISU was responsible for the development of a design for a large ${ }^{232} \mathrm{Th}$ fission chamber. This type of detector would be used to measure the fast neutrons in the spectrometer. The design consists of a large $\left(210 \mathrm{~cm}^{2}\right)$ parallel-plate back-to-back gas chamber operated in proportional counting mode. A back-toback chamber consists of two identical sides, each side being connected to a separate chain of electronics, but each side having the exact same voltage applied. One side will have the thorium-coated foil, and the other will not have a foil. The side with the thorium foil will be ionized both by fission fragments from the thorium and by gamma rays from the surrounding lead. The empty side will only be ionized by the gamma rays. Because the two sides of the chamber are back-to-back, both of them will see the same gamma flux; therefore, the output of the empty side can be subtracted from the output of the side with the foil, leaving only the pulses created by fission products generated in the thorium-coated foil. Experiments with the AmBe source show that the interrogation flux chambers produce good spectra at close-toanticipated count rates. The larger assay chambers are ready for construction, with testing and calibration to follow. More detailed information can be found in (Stewart 2013). 


\section{$2.2{ }^{4} \mathrm{He}$ Scintillator for Fast Neutron Detection}

LANL is pursuing the concept of a ${ }^{4} \mathrm{He}$ scintillator as a fast neutron detector. If successful, such a detector could provide 1-3 orders of magnitude improvement in performance compared to traditional

${ }^{232} \mathrm{Th}$ fission chambers. The ${ }^{4} \mathrm{He}$ scintillator detector was received from Duke University a few days before the end of this fiscal year. It is hoped that funding will be available in FY2014 to support experimental tests of the detector.

\subsection{Algorithm Development}

\subsection{Estimate of Neutrons Required}

LANL determined that the LSDS time-spectrum change due to any $< \pm 20 \%$ change in a single fissile isotope mass can be described as being determined by the change in that fissile isotope mass alone. In other words, such a change does not measurably perturb the neutron flux in the assembly. Consequently, we can use the deviations from a well-characterized system to determine the deviations in the fissile material mass from the characterized system as a linear combination of perturbation spectra of each one of the changed isotopes. In turn, this provides a mechanism for analysis of statistical errors inherent in any analysis process. We determined that within the context of the model we published (Gavron et al. 2009), a total neutron source of $10^{16}$ neutrons would provide a $2-3 \%$ precision in ${ }^{235} \mathrm{U}$ and ${ }^{239} \mathrm{Pu}$ masses in the used fuel bundle. This method also allows one to determine the mass of hydrogen absorbed in the cladding, and the masses of ${ }^{240} \mathrm{Pu}$ and ${ }^{241} \mathrm{Pu}$, albeit with less precision. Further details of this analysis can be found in (Gavron 2013).

\subsection{Applying Algorithms to Measurement Data}

PNNL applied various algorithms previously developed to data from measurements conducted by RPI. The measurements involved a single fresh fuel pin and discrete ${ }^{239} \mathrm{Pu}$ and ${ }^{235} \mathrm{U}$ samples. We are able to describe the isotopic fissile masses with root mean square errors over seven different configurations to $6.3 \%$ for ${ }^{239} \mathrm{Pu}$ and $2.7 \%$ for ${ }^{235} \mathrm{U}$ using the linear empirical algorithm. Significant effort is yet needed to demonstrate the applicability of these algorithms on measurements of used-fuel assemblies, but the results reported here are encouraging in demonstrating that we are making progress toward that goal. Further details can be found in (Warren et al. 2013a).

\subsection{Research Plan}

The collaboration has been working toward a goal of conducting Technical Ready Level (TRL) 5 measurements in 2014. To achieve the "operationally relevant environment" of a TRL 5 demonstration, measurements should be conducted on used-fuel assemblies. While it is possible for many of the components of the planned demonstration to be ready by 2014, a used fuel assembly for the measurements will not be available to us within that timeframe. The LSDS collaboration recommends, as an alternative, that the next step in empirically testing feasibility is to conduct measurements on fresh fuel 
assemblies to investigate self-attenuation and fresh mixed-oxide (MOX) fuel rodlets so we may better understand extraction of masses for ${ }^{235} \mathrm{U}$ and ${ }^{239} \mathrm{Pu}$. While progressing toward these goals, the collaboration also strongly suggests the continued development of enabling technology such as detector and algorithm development, which could provide significant performance benefits.

The LSDS collaboration recommends that the next demonstration measurement for the LSDS technique for assaying used fuel assembly be a pair of measurements. The first measurement will be to test the impact of self-attenuation using fresh fuel sub-assemblies. The second measurement will test the ability to extract fissile isotopes using fresh MOX fuel rodlets. As part of this effort, RPI will be the focus of the measurements, ISU will develop a thorium fission chamber, UNLV will develop a ultra depleted uranium fission chamber, LANL will test the ${ }^{4} \mathrm{He}$ recoil scintillator detector concept, and both LANL and PNNL will continue to refine algorithms. Two possible funding options have been outlined, one assuming MPACT funding only, and the other assuming cost sharing with Nuclear Energy University Program (NEUP). The detailed research plan can be found in (Warren et al. 2013b). Since the submission of the research plan, the NEUP proposal was not accepted.

\subsection{References}

Gavron, A. 2013, Implications of the Statistical Precision of LSDS Spectra in determining the Relative Contributions of Fissile Materials and Hydrogen in Spent Fuel. LA-UR-13-27067, Los Alamos National Laboratory, Los Alamos, New Mexico.

Gavron, A, LE Smith, and JJ Ressler. 2009. "Analysis of spent fuel assemblies using a lead slowing down spectrometer." Nucl Instrum Meth A 602:581-87. Doi 10.1016/J.Nima.2009.01.017

Stewart, T. 2013. Design and Calibration of Thorium Fission Chambers For Use in Lead Slowing-Down Spectroscopy. Masters Thesis, Idaho State University, Department of Nuclear Science and Engineering, Pocatello, Idaho.

Warren, GA, KK Anderson, JA Kulisek, Y Danon, A Weltz, A Gavron, JT Harris, and T Stewart. 2013a, Lead Slowing Down Spectrometry Analysis of Data from Measurements on Nuclear Fuel. PNNL-SA-98291, Pacific Northwest National Laboratory, Richland, Washington.

Warren, GA, JA Kulisek, A Gavron, Y Danon, A Weltz, JT Harris, and T Stewart. 2013b, Lead Slowing Down Spectrometer Research Plans. PNNL-22340, Pacific Northwest National Laboratory, Richland, Washington. 


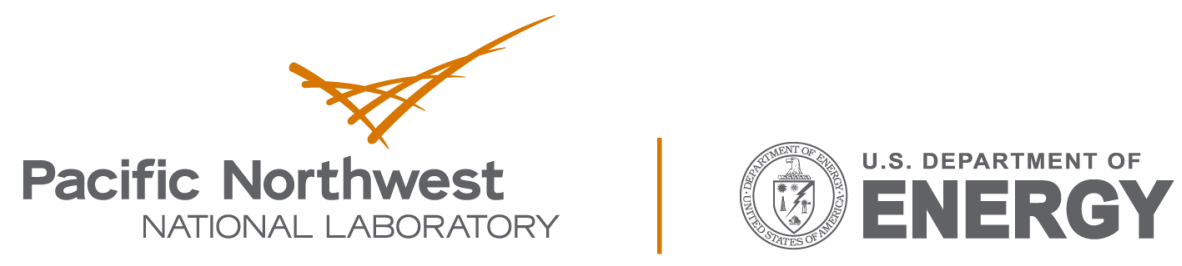

Proudly Operated by Battelle Since 1965

902 Battelle Boulevard

P.O. Box 999

Richland, WA 99352

1-888-375-PNNL (7665)

www.pnnl.gov 